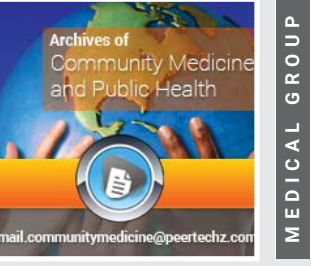

\title{
Government and Non-
}

\section{Government Responses during current situation of COVID-19 Pandemic in India}

\section{Dheeraj Sharma ${ }^{1 *}$ and Poonam Joshi ${ }^{2}$}

'Department of Community Medicine, Muzaffarnagar Medical College, Muzaffarnagar, Uttar Pradesh, India

2Department of Kaya Chikitsa, Sham-e-Ghausia Minority Ayurved Medical College and Hospital, Ghazipur, Uttar Pradesh, India

Check for updates

Received: 13 February, 2021

Accepted: 04 March, 2021

Published: 05 March, 2021

*Corresponding author: Dr. Dheeraj Sharma, Assistant Professor, Department of Community Medicine, Muzaffarnagar Medical College, Opposite Begrajpur Industrial Area, 115 Km Stone, Delhi-Dehradun Road, Muzaffarnagar, Uttar Pradesh, Pin: 251001, India, Tel: (+91) 8249143067;

E-mail: sharma.dheeraj10@gmail.com

ORCID: https://orcid.org/0000-0002-4046-5035

https://www.peertechzpublications.com

\section{Abstract}

It is not easy to recover the damage. India is now the second top country in the world in terms of total COVID-19 infection and recovering from COVID-19 infections. There have been comparatively lesser mortalities despite the high population of the country; which might be because of the predominant younger population, antibodies against the dengue virus, under-reporting of figures, and poor death reporting mechanism. The low testing rate of COVID-19 in India and dependency on the Rapid Antigen Test in some states have been a major downside. Reporting fast recovery of the cases and poor level protocol for testing have allowed the infection to go undetected and spread the disease.

The pandemic has resulted in negative socioeconomic impacts in the form of deflation in GDP, unemployment, poverty, recession, and decreased global trade. Though the Government of India has taken plenty of measures to combat the situation, there are still many areas where improvement is possible. The World Health Organization is functioning in collaboration with the Government of India and is providing technical support to the other national Government bodies. Some states did well to control the coronavirus disease, while others could not properly deal with the emergent situation within time. India has promptly and adroitly managed the pandemic situation to an extent.

\section{Introduction}

The pandemic has caused extensive damage. The toll of the global coronavirus disease at present is staggering at 115 million total cases, 21 million active cases, 91 million recoveries, and 2.5 million deaths. India has around 11 million total cases, 0.17 million active cases, 10.8 million recoveries, and 0.15 million deaths. About 217 million tests have been done to date in India, and 0.15 million tests are being done per million of population [1]. This is the Global and Indian scenario of coronavirus disease at present.

\section{Rising number of Cases}

India is the world's second top country in terms of total COVID-19 infections. The cases in India are still on the rise. Fresh infection in India was $17 \%$ in March 2020 and $7.6 \%$ in
September 2020. New infection in the United States during April 2020 was $22.3 \%$ and fell to $5.6 \%$ in September 2020, while in Italy it was $13 \%$ in April 2020 but just $2.1 \%$ in September 2020. India is also the second top country in the world in terms of recovery. The average time for recovery in India has been 11 days, which is in disagreement with the WHO recommendation of 14 days [2]. The reason for the rising number of cases in India appears to be the poor level protocol for testing. Infected cases have been declared as cured without testing. This has allowed the infection to go undetected and spread the disease.

\section{Low Mortality Rate}

India's death rate of COVID-19 has been 113 per million population, contrasted to 1593 in the United States and 1206 in Brazil. While the United States recorded 0.52 million deaths and Brazil registered 0.26 million death, India reflected only 
0.16 million deaths till now. Apart from India, the low mortality rate is also registered by other countries such as Bangladesh and Pakistan [1]. It is perplexing that India has witnessed fewer mortalities despite high population and population density, close quarters, large families, small rooms, dense slums, overcrowded public transport, and inadequate social distancing.

While the global researches indicate that the disease is particularly fatal to the elderly age group, official Indian data suggests that $43 \%$ of the people who have died from the coronavirus disease were between the ages of 30-60 years [3]. One plausible reason for this is demographics. Compared to countries in the West, South Asian nations have relatively younger population. The average age of the Indian population is 26.8 years, Pakistan is 22 years, Bangladesh is 27.9 years; while that of the United States is 38.5 years, Brazil is 33.2 years, and Italy is 45.5 years respectively. Research even suggests that antibodies against the dengue virus that is endemic in around 100 countries including India, also bestow some protection against COVID-19. India has faced criticism for underreporting COVID-19 figures. The death recording framework and reporting mechanism have been erratic for long. Even if we include the under-counted deaths in the official figures, India's death rate would still be lower than Brazil and United States [4]. The early lockdown on 25 March 2020 forced the entire country to an immediate standstill and gave India the time to extend testing centers and quarantine facilities. These have pushed a lot in slowing the spread of infection.

\section{Low Testing Rate and Antigen Test}

Although the overall number of tests undertaken in India rose from 4 million in June 2020 to 49 million in September 2020 , this was terribly low as compared to other countries specifically in relation to population. The United States had already done 19 million tests by June 2020, which advanced up to 90 million by September 2020 [2]. Per one million population; India has done 0.15 million tests to date compared to 1 million in the United States, 1.3 million tests in the United Kingdom, and 0.52 million tests in Germany [1].

India has largely depended on Rapid Antigen Test, which has a lower ability to detect COVID-19 infections as compared to the RT-PCR test. Rapid Antigen Test had been mostly used in the states like Delhi and Bihar while RT-PCR in Tamil Nadu. Delhi government in a submission to the High Court on 27 July 2020 asserted that between 18 June and 21 July, 19.3\% were COVID-19 positive when tested by RT-PCR while only $6.3 \%$ by Rapid Antigen Test. A serological survey conducted in August 2020 in Delhi suggested that $29 \%$ of Delhi's population had COVID-19 infection. Understanding the situation, Delhi increased its coronavirus testing with help of RT-PCR. This led to an increase in the detection of unrecognized cases, thereby increased the toll in Delhi [2].

\section{Socioeconomic Impact}

World Bank reports expected 5.2\% deflation in global GDP [5] and the United Nations reports apprehended 5.9\% deflation in Indian GDP in the year 2020 [6]. International
Labour Organization (ILO) told in April 2020 that lockdown has afflicted almost 2.7 billion workers worldwide and 25 million jobs are threatened ascribed to coronavirus disease [7]. India's unemployment rate in May 2020 was $24 \%$, which substantially improved and became 6\% in September 2020 [8].

The pandemic has impeded economic activity despite the efforts of governments to redress. These downturns will diminish the growth and drive millions of people around the world into utter hardship. It's a moment of the slump and reduced global trade and illustrates the poorest economy during recent decades. While the improvement is expected to take up this year, this deflation will constitute a permanent fall in income. The worst jostle of lockdown in India has been on the economically backward classes with insufficient access to healthcare and other resources.

\section{Government Response}

The Government of India focussed on the importance of comprehensive testing, rigorous contact tracing, effective and prompt treatment, institutional quarantine, containment, data analytics and transparency, leverage technology, enforcement, online training, protocol for frontline workers, public adherence, and community participation [9]. The Government of India took various measures for the safety of health workers at the forefront in the fight against COVID-19 e.g., Human resources, medical safety, timely payment, psychological support, capacity building, and life insurance cover [10]. Under the Pradhan Mantri Garib Kalyan Yojana, the Government provided 312 billion Indian rupees to around 331 million beneficiaries that encompassed women, construction workers, farmers, and senior citizens. It also provided aid to support small businesses going through the crisis [8]. These swift and extensive measures controlled the infection in India, empowered frontline health workers, and supported the lower socio-economic section of society.

India managed this pandemic with good infrastructure, sufficient drug stock, timely lockdown, thermal screening, good health system, and innovation. The major downside has been community barriers and lack of testing kits, personal protective equipment, ventilators, emergency infrastructure, and professionals. It can develop institutional infrastructure policies, vaccines, and innovation; but must simultaneously take care to avert the possibilities of community transmission, breach of lockdown, contraction of the disease, failure of contact tracing, and the collapse of socioeconomic growth [11].

\section{Non-Government Organization Response}

The WHO Country Office for India worked in close partnership with the Government of India to step up preparedness and response measures for COVID-19; and provided technical support to the Ministry of Health \& Family Welfare, National Centre for Disease Control, Indian Council of Medical Research, National Disaster Management Authority, and NITI Aayog [12]. This multi-pronged approach of WHO by collaborating with different national Government bodies has been tremendously helpful for the needful coordinated response to control the coronavirus disease. 


\section{Unequal States Responses}

Management of public health in India is done at the state level. States like Kerala isolated patients early, traced and quarantined contacts, and tested aggressively. Contrary to it, Delhi faced criticism for failing to control cases when lockdown measures eased. There are reports of the death of patients in Delhi after denial from admission from COVID-19 designated hospitals. This led the Home Ministry to meddle and allocate 500 railway cars as makeshift hospital wards [3].

The reasons behind the spike of cases in Delhi were poor mask discipline among the people, the coincidence of reopening the city and rise in the number of cases, the plateau in tests and dependency on the rapid antigen test, and changing statistics (incubation period, delay in test results, and age of patients). Enforcing regulation, enhancing testing, using RT-PCR, monitoring of positivity and doubling rate, and watching over any sign of the emergence of second-wave were the measures that could control the situation [13].

\section{Conclusion}

Despite the timely lockdown, cases of COVID-19 infection in India have skyrocketed. One of the causes of lower mortalities in India appears to be the predominant younger population, but the under-reporting of cases and the poor death reporting mechanism have made a hazy picture of the situation. The immediate focus should be on testing with RT-PCR. Protocol for testing should be followed to prevent the spread of infection. Though the World Health Organization, the Government of India, and other national Government bodies have worked hard to minimize the damage caused by the pandemic, there are still many areas where improvement is possible. States with poor performance in the control of coronavirus disease can learn from its failures and the success of good performing states. Overall, India has attempted well to control the coronavirus disease.

\section{References}

1. Worldmeter (2021) Coronavirus Update (Live): 103,725,995 Cases and 2,242,324 Deaths from COVID-19 Virus Pandemic - Worldometer. Link: http://bit.ly/3bXPiFb

2. Gera I (2020) Coronavirus pandemic problem: Here's why India's Covid-19 curve is still rising - The Financial Express. Financial Express. Link: http://bit.ly/2NRdMYX

3. AP. Why India coronavirus cases are rising to multiple peaks. Arab News 45 Link: http://bit.ly/2MQvtHy

4. Basu M (2020) Why India's Covid death numbers are lower than US, Brazil while cases rise at a higher pace. The Print. Link: http://bit.ly/388RrNa

5. The World Bank. The Global Economic Outlook During the COVID-19 Pandemic: A Changed World. The World Bank Group. Link: http://bit.ly/2OiOaUw

6. United Nations. Indian economy to contract $5.9 \%$ in 2020 due to Covid-19 disruptions, says UN report - business news - Hindustan Times. Hindustan Times. Link: Link: http://bit.ly/3bgsYHY

7. United Nations. COVID-19: impact could cause equivalent of 195 million job losses, says ILO chief. UN News. UN News. Link: http://bit.ly/2PzSf7t

8. Keelery S (2021) India: unemployment rate due to COVID-19. Statista. Statista. Link: http://bit.ly/3becksa

9. Kant A (2020) Managing Coronavirus: Learning from Global Best Practices NITI Aayog. Government of India. Link: https://bit.ly/20pc7JG

10. Sudan P (2020) Measures Undertaken To Ensure Safety of Health Workers Drafted For COVID-19 Services. Link: http://bit.ly/2PoXXsE

11. NITI Aayog (2020) Covid-19 in India: A Swot Analysis. NITI Aayog. Government of India. Link: https://bit.ly/2MNcgq8

12. World Health Organization (2020) South East Asia. India. Coronavirus Disease (COVID-19). Link: http://bit.ly/3rhwN50

13. Mullick J (2020) 5 reasons why Delhi's Covid-19 cases spiked. India news. Hindustan Times. Link: http://bit.ly/3uViAge

Discover a bigger Impact and Visibility of your article publication with Peertechz Publications

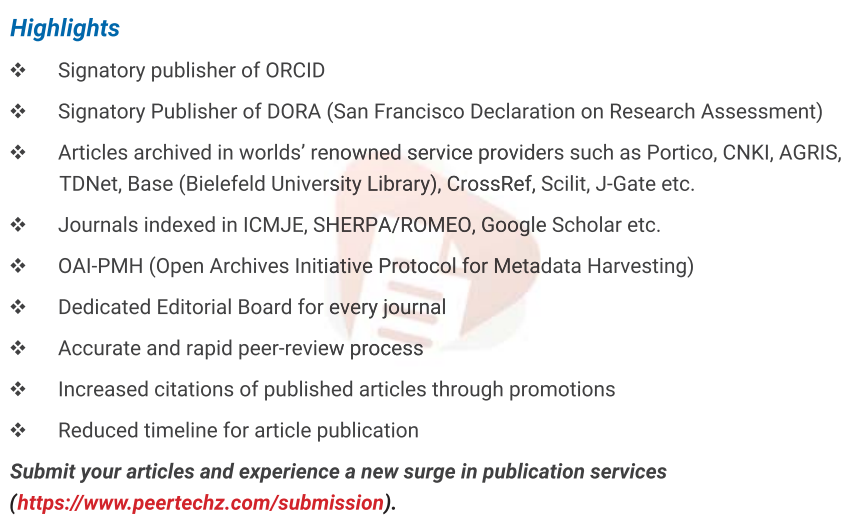

Peertechz journals wishes everlasting success in your every endeavours.

Copyright: @ 2021 Sharma D, et al. This is an open-access article distributed under the terms of the Creative Commons Attribution License, which permits unrestricted use, distribution, and reproduction in any medium, provided the original author and source are credited. 